\title{
Impact of neuroradiologist second opinion on staging and management of head and neck cancer
}

\author{
John T Lysack ${ }^{1,2,3,4^{*}}$, Monica Hoy², Mark E Hudon', Steven C Nakoneshny ${ }^{3}$, Shamir P Chandarana ${ }^{2,3}$, \\ T Wayne Matthews ${ }^{2,3}$ and Joseph C Dort ${ }^{2,3}$
}

\begin{abstract}
Objective: Patients with head and neck cancer frequently present to academic tertiary referral centers with imaging studies that have been performed and interpreted elsewhere. At our institution, these outside head and neck imaging studies undergo formal second opinion reporting by a fellowship-trained academic neuroradiologist with expertise in head and neck imaging. The purpose of this study was to determine the impact of this practice on cancer staging and patient management.

Methods: Our institutional review board approved the retrospective review of randomized original and second opinion reports for 94 consecutive cases of biopsy proven or clinically suspected head and neck cancer in calendar year 2010. Discrepancy rates for staging and recommended patient management were calculated and, for the $32 \%$ (30/94) of cases that subsequently went to surgery, the accuracies of the reports were determined relative to the pathologic staging gold standard.

Results: Following neuroradiologist second opinion review, the cancer stage changed in 56\% (53/94) of cases and the recommended management changed in 38\% (36/94) of patients with head and neck cancer. When compared to the pathologic staging gold standard, the second opinion was correct 93\% (28/30) of the time.

Conclusion: In a majority of patients with head and neck cancer, neuroradiologist second opinion review of their outside imaging studies resulted in an accurate change in their cancer stage and this frequently led to a change in their management plan.
\end{abstract}

Keywords: Second opinion, Radiology, Cancer staging, Head and neck cancer, Quality improvement

\section{Introduction}

Despite advances in diagnosis and treatment, head and neck cancer remains an important cause of death and disability worldwide. The most recent global estimates from the World Health Organization indicate that 845,000 new cases of head and neck cancer are diagnosed each year, with a mortality rate approaching $50 \%$ [1].

Head and neck cancer may present with a variety of symptoms and signs depending, in part, on the site of

\footnotetext{
* Correspondence: john.lysack@ucalgary.ca

'Division of Neuroradiology, University of Calgary, Calgary, Alberta, Canada 2Division of Otolaryngology-Head and Neck Surgery, University of Calgary, Calgary, Alberta, Canada

Full list of author information is available at the end of the article
}

the primary tumor. The diagnosis is usually made or suspected on the basis of the clinical examination and confirmed with a biopsy of the primary lesion or a metastatic lymph node. The most important prognostic factor, after primary site, tumor type, and tumor grade, is cancer stage and, all else being equal, highstage cancers have a poorer prognosis than low-stage cancers. Cancer stage is also a major consideration when determining appropriate treatment. For example, for some primaries, the recommended management is surgical for low-stage cancers and nonsurgical (e.g. chemoradiotherapy) for high-stage cancers. Because the primary site is usually identified clinically, and the tumor type and grade are determined by pathology, the main role of imaging in the initial management of

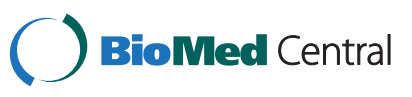


patients with head and neck cancer is to facilitate accurate staging.

At academic tertiary referral centers, patients frequently present with imaging studies that have been performed and interpreted elsewhere [2]. At our institution, all outside head and neck imaging studies undergo formal reinterpretation by a fellowship-trained academic neuroradiologist with expertise in head and neck imaging prior to discussion of the case at a weekly multidisciplinary tumor board. At the weekly tumor board, the multidisciplinary team reviews the clinical, pathological, and imaging data, the cancer stage is determined, and a treatment recommendation is made. The purpose of this study was to determine how frequently the neuroradiology second opinion changed staging and management, and to estimate how frequently the second opinion was accurate when compared with surgical findings.

\section{Methods}

Our institutional review board (The University of Calgary Conjoint Health Research Ethics Board) approved the retrospective review of patient data for this study, and waived the requirement for informed consent. All cases $(n=94)$ of biopsy proven or clinically suspected head and neck cancer presenting to our academic tertiary referral center with outside computed tomography (CT) or magnetic resonance (MR) imaging during the 2010 calendar year were retrospectively identified from our institutional head and neck cancer database (Table 1). As part of our routine practice, a fellowship-trained academic neuroradiologist with expertise in head and neck imaging and three years of post-fellowship experience had issued a formal second opinion report in all cases. Hardcopies of the original and second opinion reports were collected, randomized, and distributed to three reviewers: a fellowship-trained academic head and neck surgeon with 20 years of post-fellowship experience, an otolaryngology-head and neck surgery resident with four years of residency experience, and a fellowship-trained academic neuroradiologist with 15 years of post-fellowship experience (a different neuroradiologist than the one who had issued the second opinion reports).

The three reviewers independently analyzed each of the 188 randomized reports (94 original radiology reports and 94 second opinion reports) and recorded the primary site, T-category (extent of primary tumor), and $\mathrm{N}$-category (extent of cervical lymph node metastases) using the most recent American Joint Committee on Cancer definitions [3], as could be determined from the information found in each radiology report. To determine the reliability of the data, the inter-rater agreements
Table 1 Patient and tumor characteristics

\begin{tabular}{|c|c|c|}
\hline Variable & $\begin{array}{l}\text { All cases } \\
(n=94)\end{array}$ & $\begin{array}{l}\text { Surgical cases } \\
\qquad(n=30)\end{array}$ \\
\hline Age $(y)$, mean (range) & $61.6(31.1,90.1)$ & $65.2(36.3,89.7)$ \\
\hline Gender (M:F) & $70: 24$ & $17: 13$ \\
\hline \multicolumn{3}{|l|}{ Primary } \\
\hline Oral Cavity & $24(25.5 \%)$ & $19(63.3 \%)$ \\
\hline Oropharynx & $22(23.4 \%)$ & $2(6.7 \%)$ \\
\hline Hypopharynx & $2(2.1 \%)$ & $0(0.0 \%)$ \\
\hline Larynx & $15(16.0 \%)$ & $3(10.0 \%)$ \\
\hline Salivary Gland & $6(6.4 \%)$ & $3(10.0 \%)$ \\
\hline NC \& PNS & $5(5.3 \%)$ & $2(6.7 \%)$ \\
\hline Nasopharynx & $7(7.4 \%)$ & $0(0.0 \%)$ \\
\hline Thyroid & $1(1.1 \%)$ & $0(0.0 \%)$ \\
\hline Unknown & $5(5.3 \%)$ & $0(0.0 \%)$ \\
\hline Skin & $4(4.3 \%)$ & $1(3.3 \%)$ \\
\hline Lymphoma & $3(3.2 \%)$ & $0(0.0 \%)$ \\
\hline \multicolumn{3}{|l|}{ Stage } \\
\hline Benign & $2(2.1 \%)$ & $1(3.3 \%)$ \\
\hline Stage 0 & $3(3.2 \%)$ & $2(6.7 \%)$ \\
\hline Stage I & $9(9.6 \%)$ & $4(13.3 \%)$ \\
\hline Stage II & $3(3.2 \%)$ & $2(6.7 \%)$ \\
\hline Stage III & $9(9.6 \%)$ & $3(10.0 \%)$ \\
\hline Stage IV & $68(72.3 \%)$ & $18(60.0 \%)$ \\
\hline
\end{tabular}

NC \& PNS, Nasal Cavity and Paranasal Sinuses.

for T-category and N-category for the original and second opinion reports were calculated using Fleiss' $\kappa$ for multiple raters [4]; the opinion of the head and neck surgeon was considered the gold standard.

The cancer stage ('Stage 0-IV') was calculated from the $\mathrm{T}$-category and $\mathrm{N}$-category data according to the most recent American Joint Committee on Cancer definitions [3], as all patients had no evidence of distant metastases. Staging data were then dichotomized into low-stage (Stage 0, I, or II) vs. high-stage (Stage III or IV) groups ('Low/High Stage'), and into nodenegative (N0) vs. node-positive (N1, N2, or N3) groups ('Node Negative/Positive'). The staging data derived from the original reports were compared with those from the second opinion reports, and discrepancy rates with 95\% confidence intervals (95\% CI) were calculated using the modified Wald method [5]. If there was a change in staging from the original report to the second opinion, the direction of change (up-staging vs. down-staging) was determined.

The head and neck surgeon also made a recommendation for patient management based on the information provided in each radiology report. He was asked, "Assuming that the information in the radiology report is 
correct and agrees with your clinical impression, and that the patient is agreeable, otherwise healthy, and has no contraindications, what initial management would you recommend?" His choices were: (a) surgery (resection of the primary tumor +/-lymph node dissection); (b) radiotherapy (+/-chemotherapy); (c) no treatment; and (d) don't know. For the 'don't know' cases, the surgeon recorded the reason. The surgeon's management recommendations based on the original reports were compared with those based on the second opinion reports, and discrepancy rates with $95 \%$ confidence intervals $(95 \% \mathrm{CI})$ were calculated using the modified Wald method [5]. Fisher's exact test [6] was used to reject the null hypothesis that the surgeon's management recommendations based on the original and second opinion reports were the same.

For the subgroup of cases $(n=30)$ in which surgery was subsequently performed, pathologic staging data were acquired from pathology reports. The radiologic staging data were compared to the pathologic staging data and the accuracies of the original and second opinion reports were calculated. Fisher's exact test [6] was used to reject the null hypothesis that the accuracies for cancer stage of the original and second opinion reports were the same.

All tests were two-sided tests using a threshold for statistical significance of $P<.05$. Statistical analysis was performed using Stata 11 (StataCorp, College Station, TX).

\section{Results}

The staging data that were extracted from the radiology reports were found to be reliable. There was 'moderate' to 'substantial' inter-rater agreement for the original reports $(\kappa=0.44$ for $\mathrm{T}$-category and $\mathrm{K}=0.78$ for $\mathrm{N}$ category) and 'substantial' to 'almost perfect' agreement for the second opinion reports $(\kappa=0.62$ for T-category and $\mathrm{K}=0.89$ for N-category) [7].

The discrepancy rate for cancer stage (Stage 0-IV) was $56.4 \%$ (95\% CI, 46.3\% - 65.9\%); the discrepancy rates for staging ranged from a low of $34.0 \%$ (95\% CI, $25.2 \%$ 44.1\%) for both Low/High Stage and Node Negative/ Positive to a high of $66.0 \%$ (95\% CI, $55.9 \%-74.8 \%$ ) for T-category (Table 2). Up-staging was common, occurring in $90.6 \%(48 / 53$; 95\% CI, 79.3\% - 96.3\%) of discrepant cases.

Pathologic staging data were available for the 30/94 $(31.9 \%)$ of cases in which surgery was subsequently performed (Table 3). When compared to the entire group, the surgical subgroup had a higher proportion of oral cavity primaries and a lower proportion of oropharyngeal primaries (Table 1), which reflects the fact that oral cavity cancers are usually treated surgically while oropharyngeal cancers are usually treated with
Table 2 Discrepancies in cancer staging between the original and second opinion radiology reports

\begin{tabular}{lcc}
\hline Staging criteria & $\begin{array}{c}\text { All cases } \\
(\mathbf{n = 9 4 )}\end{array}$ & $\begin{array}{c}\text { Surgical cases } \\
(\mathbf{n = 3 0 )}\end{array}$ \\
\hline T-category & $62(66.0 \%)$ & $18(60.0 \%)$ \\
N-category & $50(53.2 \%)$ & $13(43.3 \%)$ \\
Stage (0-IV) & $53(56.4 \%)$ & $17(56.7 \%)$ \\
Low/High Stage & $32(34.0 \%)$ & $11(36.7 \%)$ \\
Node Negative/Positive & $32(34.0 \%)$ & $9(30.0 \%)$ \\
\hline
\end{tabular}

radiotherapy $+/$-chemotherapy at our institution. In the surgical cases, the original radiology reports agreed with the pathologic stage (Stage 0-IV) 40.0\% $(12 / 30)$ of the time (Table 4$)$ whereas the second opinion reports agreed with the pathologic stage 93.3\% $(28 / 30)$ of the time $(P<.001)$. Following the second opinion, the cancer stage changed in $56.7 \%$ $(17 / 30)$ of the surgical cases, and these changes were pathologically proven to be correct $94.1 \%$ (16/17) of the time (Figure 1).

The discrepancy rate for patient management was $38.3 \%$ (36/94; 95\% CI, 29.1\%-48.4\%); most changes $(77.8 \%$; 28/36) were from 'don't know' based on the original report to one of surgery or radiotherapy (+/-chemotherapy) based on the second opinion report (Table 5). It was not possible for the surgeon to make a management recommendation based on either the original report or the second opinion report in 29.8\% (28/ 94) of cases. In most of these cases $(75.0 \% ; 21 / 28)$, this was because of a technically inadequate or incomplete scan for which the radiologist recommended additional imaging, or a post-treatment recurrence for which the surgeon needed details of prior treatment before making a treatment decision. Despite this, the management recommendation based on the second opinion reports agreed with the actual management $60.0 \%$ (18/30; $95 \%$ CI, $42.3 \%-75.4 \%)$ of the time, as compared to $33.3 \%$ $(10 / 30$; $95 \% \mathrm{CI}, 19.1 \%-51.3 \%)$ of the time for the original reports $(P=.069)$.

\section{Discussion}

Our study demonstrates the value of reinterpretation of head and neck imaging studies by a fellowship-trained academic neuroradiologist; such reinterpretation led to more accurate staging and better treatment decisionmaking. We found that, following formal second opinion reporting of outside imaging studies, there was a change in cancer stage in $56 \%$ of cases, resulting in a change in management in $38 \%$ of patients; for the surgical cases, the second opinions were pathologically proven to be correct $93 \%$ of the time.

These findings add to the evidence that subspecialty radiologist interpretation of imaging studies has a 
Table 3 Cancer staging and recommended management based on the original and se1cond opinion radiology reports compared to the pathologic staging gold standard $(n=30)$

\begin{tabular}{|c|c|c|c|c|c|c|c|c|c|}
\hline \multirow[b]{2}{*}{$\mathrm{Pt}$} & \multirow[b]{2}{*}{ Age } & \multirow[b]{2}{*}{$M / F$} & \multirow[b]{2}{*}{ Primary } & \multicolumn{3}{|c|}{ Staging } & \multicolumn{3}{|c|}{ Management } \\
\hline & & & & Original & Second opinion & Pathologic & Original & Second opinion & Actual \\
\hline $\bar{A}$ & 89 & $\mathrm{~F}$ & Oral Cavity & TXNO & T4aN2b & T4aNo & Don't know ${ }^{\dagger}$ & Surgery & $\overline{\text { Surgery }}$ \\
\hline$B$ & 55 & M & Oral Cavity & TONO & T1N1 & $\mathrm{T} 2 \mathrm{~N} 1$ & No treatment & Surgery & Surgery \\
\hline$C$ & 84 & $\mathrm{~F}$ & Oral Cavity & T2NO & T2NO & $\mathrm{T} 2 \mathrm{~N} 2 \mathrm{~b}$ & Surgery & Surgery & Surgery \\
\hline $\mathrm{D}$ & 40 & M & NC \& PNS & TONO & T3Nx & T3Nx & No treatment & Don't know ${ }^{\ddagger}$ & Surgery \\
\hline$E$ & 51 & $\mathrm{~F}$ & Oral Cavity & TXNO & TXNO & TisNo & Surgery ${ }^{*}$ & Surgery ${ }^{*}$ & Surgery \\
\hline $\mathrm{F}$ & 36 & M & Oral Cavity & TxNx & T4aNo & T4aNO & Don't know ${ }^{\dagger}$ & Don't know ${ }^{\ddagger}$ & Surgery \\
\hline G & 68 & M & Larynx & TxNx & T1N0 & T1NO & Don't know ${ }^{\dagger}$ & Surgery & Surgery \\
\hline $\mathrm{H}$ & 75 & $\mathrm{~F}$ & Oral Cavity & $\mathrm{T} 1 \mathrm{~N} 2 \mathrm{~b}$ & $\mathrm{~T} 1 \mathrm{~N} 2 \mathrm{~b}$ & $\mathrm{~T} 1 \mathrm{~N} 2 \mathrm{C}$ & Surgery & Surgery & Surgery \\
\hline I & 74 & M & Salivary Gland & T2NO & T2NO & T2NO & Surgery & Surgery & Surgery \\
\hline$J$ & 69 & M & Larynx & T4aN1 & $\mathrm{T} 4 \mathrm{aN} 2 \mathrm{~b}$ & $\mathrm{~T} 4 \mathrm{aN1}$ & Surgery & Surgery & Surgery \\
\hline K & 61 & M & Oral Cavity & TXNO & T2NO & T2NO & Don't know ${ }^{\dagger}$ & Surgery & Surgery \\
\hline $\mathrm{L}$ & 80 & $\mathrm{~F}$ & Oral Cavity & T2NO & T1N1 & $\mathrm{T} 2 \mathrm{~N} 2 \mathrm{~b}$ & Surgery & Surgery & Surgery \\
\hline M & 54 & M & Oropharynx & TxN1 & T1N1 & T1N1 & $\mathrm{RT}^{\S}$ & $\mathrm{RT}^{\S}$ & Surgery \\
\hline $\mathrm{N}$ & 82 & $\mathrm{~F}$ & Oral Cavity & TONO & TONO & TONO & Don't know ${ }^{\ddagger}$ & Don't know $^{\ddagger}$ & Surgery \\
\hline $\mathrm{O}$ & 49 & $\mathrm{~F}$ & Oral Cavity & TONO & T1NO & T1NO & No treatment & Don't know ${ }^{\ddagger}$ & Surgery \\
\hline$P$ & 70 & M & Larynx & T4aNO & $\mathrm{T} 4 \mathrm{aN} 2 \mathrm{c}$ & T4aNo & Surgery & Surgery & Surgery \\
\hline$Q$ & 90 & M & Oral Cavity & TxN1 & $\mathrm{T} 2 \mathrm{~N} 1$ & $\mathrm{~T} 2 \mathrm{~N} 1$ & Don't know ${ }^{\dagger}$ & Don't know ${ }^{\ddagger}$ & Surgery \\
\hline $\mathrm{R}$ & 85 & $\mathrm{~F}$ & NC \& PNS & TXNO & T4aNo & T4aNO & Don't know ${ }^{\dagger}$ & Don't know ${ }^{\diamond}$ & Surgery \\
\hline S & 56 & M & Oral Cavity & TXNO & T4aNo & $\mathrm{T} 4 \mathrm{aN} 2 \mathrm{~b}$ & Surgery ${ }^{*}$ & Surgery & Surgery \\
\hline $\mathrm{T}$ & 58 & M & Oral Cavity & $\mathrm{T} 4 \mathrm{aNx}$ & T4aN2c & T4aN1 & Don't know ${ }^{\dagger}$ & Surgery & Surgery \\
\hline$U$ & 45 & M & Salivary Gland & T1NO & T1NO & T1NO & Surgery & Surgery & Surgery \\
\hline V & 88 & $\mathrm{~F}$ & Oral Cavity & TxN1 & T4aN1 & T4aN1 & Don't know ${ }^{\dagger}$ & Surgery & Surgery \\
\hline W & 56 & $\mathrm{~F}$ & Oral Cavity & TONO & TXNO & TisNo & No treatment & Don't know ${ }^{\ddagger}$ & Surgery \\
\hline$x$ & 43 & M & Oropharynx & TxN2a & $\mathrm{T} 2 \mathrm{~N} 2 \mathrm{~b}$ & $\mathrm{~T} 2 \mathrm{~N} 2 \mathrm{~b}$ & Don't know ${ }^{\dagger}$ & $\mathrm{RT}^{\S}$ & Surgery \\
\hline Y & 50 & $\mathrm{~F}$ & Oral Cavity & T1NO & T1N0 & T1No & Don't know ${ }^{\ddagger}$ & Don't know ${ }^{\ddagger}$ & Surgery \\
\hline Z & 81 & M & Oral Cavity & TxN1 & $\mathrm{T} 2 \mathrm{~N} 2 \mathrm{~b}$ & $\mathrm{~T} 2 \mathrm{~N} 2 \mathrm{~b}$ & Don't know ${ }^{\dagger}$ & Surgery & Surgery \\
\hline AA & 81 & M & Skin & $\mathrm{TxN} 2 \mathrm{~b}$ & TxN2b & TxN2b & Don't know ${ }^{\diamond}$ & Don't know ${ }^{\diamond}$ & Surgery \\
\hline$A B$ & 58 & $\mathrm{~F}$ & Oral Cavity & $\mathrm{T} 2 \mathrm{~N} 2 \mathrm{~b}$ & $\mathrm{~T} 2 \mathrm{~N} 2 \mathrm{~b}$ & $\mathrm{~T} 2 \mathrm{~N} 2 \mathrm{~b}$ & Don't know ${ }^{\ddagger}$ & Don't know ${ }^{\ddagger}$ & Surgery \\
\hline$A C$ & 63 & $\mathrm{~F}$ & Salivary Gland & T3NO & T4aN2b & T4aN1 & Surgery & Surgery & Surgery \\
\hline$A D$ & 65 & M & Oral Cavity & TxN1 & $\mathrm{T} 2 \mathrm{~N} 2 \mathrm{~b}$ & $\mathrm{~T} 2 \mathrm{~N} 2 \mathrm{~b}$ & Don't know ${ }^{\dagger}$ & Surgery & Surgery \\
\hline
\end{tabular}

F, Female; M, Male; NC \& PNS, Nasal Cavity and Paranasal Sinuses; Pt, Patient Identifier; RT, Radiotherapy (+/-chemotherapy).

" Biopsy proven oral cavity cancer was stated in the Clinical History section of the report.

${ }^{\dagger}$ Insufficient information in the report to make a recommendation.

₹ Technically inadequate or incomplete scan; the radiologist recommended additional imaging.

${ }^{\S}$ Oropharyngeal carcinoma is usually treated with primary radiotherapy (+/-chemotherapy) at our institution.

$\checkmark$ Post-treatment recurrence; the surgeon needed details of prior treatment before making a salvage treatment decision.

positive impact on patient care. In the head and neck cancer domain, this was first reported by Loevner et al [8]; the authors found a change in cancer stage in 34\% of cases and a change in management in $40 \%$ of patients following expert radiologist reinterpretation. More recently, Wheless et al [9] showed that, following case review at a multidisciplinary head and neck tumor board, $27 \%$ of patients had a change in tumor diagnosis, stage, or treatment plan. In other oncological and non- oncological domains, studies of radiologist second opinions have found discrepancy rates of $11-49 \%$ for diagnosis or staging and $7-37 \%$ for patient management [10-16]. These rates are similar to those found for expert second opinions in pathology, with reported discrepancy rates of $7-66 \%$ (including changes from a benign to a malignant diagnosis or vice versa) resulting in a change in patient management in 1-28\% [17-28]. There is much less literature on the effect of expert second opinions in 
Table 4 Accuracies of the original and second opinion radiology reports compared to the pathologic staging gold standard $(\mathbf{n}=\mathbf{3 0})$

\begin{tabular}{lcc}
\hline Staging criteria & Original report & Second opinion \\
\hline T-category & $43.3 \%(27.4 \%-60.8 \%)$ & $93.3 \%(77.6 \%-99.2 \%)$ \\
N-category & $56.7 \%(39.2 \%-72.6 \%)$ & $70.0 \%(52.0 \%-83.5 \%)$ \\
Stage (0-IV) & $40.0 \%(24.6 \%-57.7 \%)$ & $93.3 \%(77.6 \%-99.2 \%)$ \\
Low/High Stage & $60.0 \%(42.3 \%-75.4 \%)$ & $96.7 \%(81.9 \%-99.9 \%)$ \\
Node Negative/Positive & $70.0 \%(52.0 \%-83.5 \%)$ & $86.7 \%(69.7 \%-95.3 \%)$ \\
\hline
\end{tabular}

Data in parentheses are $95 \%$ confidence intervals.

clinical practice, but one study [29] has shown discrepancy rates for diagnosis and patient management of $35 \%$ and $67 \%$, respectively.

New insights into differences in biological behaviors of head and neck cancers are leading to personalized treatment options that are becoming increasingly diverse. Parallel to this trend are advances in biologic imaging of head and neck cancer that are used to select the most appropriate treatment regimen for each individual patient [30]. As imaging techniques become more complex, the frequency of clinically significant differences in interpretation are expected to increase. Although a change in diagnosis following subspecialist reinterpretation of an imaging study does not necessarily imply a correct change in diagnosis, "second opinion best reflects a measure of diagnostic precision, which is a practical surrogate for diagnostic accuracy, given the difficulties of defining a gold standard" [31]. Thus, despite their costs in terms of increased and often uncompensated workload [2], it is likely that subspecialist second opinions will become increasingly important for highquality patient care.

In general radiology practice, where there is the usual mixture of normal with abnormal cases, the discrepancy rate is only $3 \%$ [32]. However, for patient populations with $100 \%$ prevalence of disease, like those served by multidisciplinary tumor boards at academic tertiary referral centers, the discrepancy rate can increase by an order of magnitude [33]. The benefit of a subspecialist model of radiology practice is highlighted by a recent study [34] that showed the discrepancy rate between fellowship-trained academic neuroradiologists was only $2 \%$ despite the high prevalence of disease (92\%) in that environment. A strength of the present study is that each radiology report was independently analyzed for staging information by three physician reviewers; an experienced fellowship-trained academic head and neck surgeon, a senior otolaryngology-head and neck surgery resident, and an experienced fellowship-trained academic neuroradiologist (a different neuroradiologist than the one who had issued the second opinion reports). The greater inter-rater agreement found for the second opinion reports supports the assertion that imaging reinterpretation by a subspecialist radiologist results in improved diagnostic precision.

The weaknesses of the current study are its retrospective nonblinded design and the absence of a pathologic gold standard in the nonsurgical cases. We chose a retrospective design to decrease the potential bias of secondary gain by the reinterpreting neuroradiologist who, if he knew his second opinion reports were to be subsequently scrutinized in a prospective study, might be
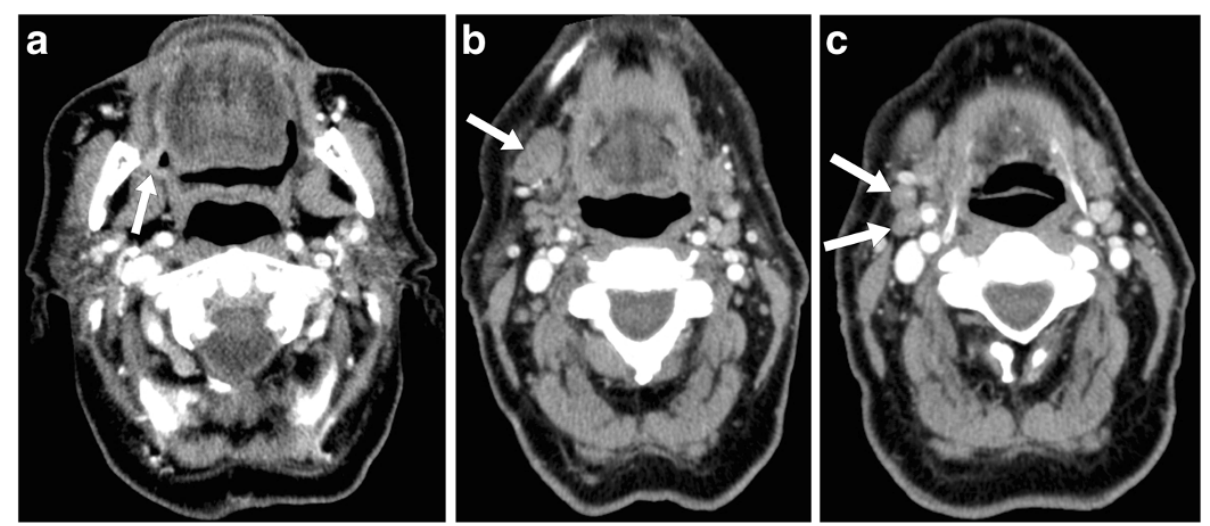

Figure 1 Axial contrast enhanced CT images of the neck in an 81 year old male (Patient $Z$ in Table 3); a fine needle aspiration biopsy of a clinically enlarged right submandibular lymph node had shown squamous cell carcinoma. (a) A plaque-like $(2.5 \mathrm{~cm}$ in diameter $X$ $0.5 \mathrm{~cm}$ in maximum thickness) enhancing mucosal lesion involving the right retromolar trigone (arrow) was not mentioned in the original radiology report but was identified as the primary tumor in the second opinion report. (b) An enlarged $(2.3 \mathrm{~cm} \times 1.5 \mathrm{~cm})$ right level IB lymph node (arrow) was interpreted as metastatic in both the original and second opinion reports. (c) Two sub-centimeter but rounded and asymmetrically prominent right level IIA lymph nodes (arrows) were not mentioned in the original report but were interpreted as metastatic in the second opinion report. Staging was TxN1 based on the original report and T2N2b (Oral Cavity) based on the second opinion report, and the recommended management was 'don't know' based on the original report (because the primary tumor location and T-category were unclear) and 'surgery' based on the second opinion report. Surgery was subsequently performed and the final pathologic staging was T2N2b (Oral Cavity). 
Table 5 Differences in recommended management based on the original and second opinion radiology reports

\begin{tabular}{lccccc}
\hline \multirow{2}{*}{$\begin{array}{c}\text { Recommended } \\
\text { management }\end{array}$} & & \multicolumn{2}{c}{ Based on second opinion report } \\
\cline { 3 - 4 } & & Surgery & RT & No treatment & $0(0.0 \%)$ \\
Based on original report & Surgery & $14(14.9 \%)$ & $1(1.1 \%)$ & $0(0.0 \%)$ & $1(1.1 \%)$ \\
& RT & $0(0.0 \%)$ & $15(16.0 \%)$ & $1(1.1 \%)$ & $1(1.1 \%)$ \\
& No treatment & $1(1.1 \%)$ & $1(1.1 \%)$ & $1(1.1 \%)$ & $2(2.1 \%)$ \\
& Don't know & $16(17.0 \%)^{*}$ & $12(12.8 \%)^{\dagger}$ & $29.8 \%)$ \\
\hline
\end{tabular}

RT, Radiotherapy (+/-chemotherapy).

${ }^{*} P<.001$.

${ }^{+} P=.002$.

motivated to exaggerate differences of opinion. The trade-off was to accept that the type of report (original vs. second opinion) could not be adequately blinded to the reviewers. Even if the name of the reporting radiologists and the location of the study were removed from the reports, it would be clear, based on the content and style of the report, which were second opinions. For example, imaging findings or interpretations from the original radiology reports (both correct and incorrect), as well as clinical information that might only be known at the time of the second opinion, were routinely acknowledged and discussed in the body of the second opinion reports. It was therefore not possible to redact such identifying information without substantially changing the content of the reports. Because of this, it is possible that the reviewers were biased to assign a greater degree of certainty to information contained in reports they knew to be second opinions. This would be expected to be more of a problem for the patient management recommendation component of the study than for the cancer staging component and might, at least in part, explain the relatively high frequency of 'don't know' recommendations for the original reports. However, this bias reflects the reality of clinical practice in which subspecialists may more frequently seek out additional information as is needed to provide a definitive opinion. Arguably, therefore, blinding the reviewers in this way would make the results less generalizable by inaccurately reflecting routine practice. The randomized presentation of the reports to the reviewers partially offsets this bias.

Establishing a gold standard for staging is difficult for many head and neck cancers. Using surgical pathology as the gold standard is problematic, as many patients do not undergo surgery (e.g. some tumors are primarily treated with radiotherapy) and, in those cases where surgery is performed, pathologic staging might be incomplete (e.g. local tumor resection but no lymph node dissection), inaccurate (e.g. is the muscle being infiltrated by tumor on this slide an intrinsic or extrinsic muscle of the tongue?), or insufficient (e.g. was there impaired vocal cord mobility or vocal cord fixation?). Even in cases where complete and sufficient pathologic staging information is available, it is only accurate at the time of surgery and not at the time of the scan. However, an error introduced by a scan-to-surgery delay would apply equally to the original and second opinion reports so, at minimum, the relative increase in accuracy found for the second opinion reports in this study is valid.

\section{Conclusion}

More than one-half of patients with head and neck cancer had a change in clinical stage following second opinion review of their outside imaging studies by a fellowship-trained academic neuroradiologist with expertise in head and neck imaging, and this led to a change in management in greater than one-third of patients. In patients with a biopsy proven or clinically suspected malignancy, subspecialty radiologist interpretation of imaging studies has a positive impact on patient care.

\section{Competing interests}

The authors declare that they have no competing interest.

\section{Authors' contributions}

$J \mathrm{~L}$ and $J D$ are responsible for study design, data collection, data analysis, and manuscript preparation. $\mathrm{MH}$ and $\mathrm{MEH}$ are responsible for data collection and manuscript preparation. SN is responsible for statistical analysis and manuscript preparation. SC and TWM are responsible for manuscript preparation. All authors read and approved the final manuscript.

\section{Acknowledgement}

This material has never been published and is not currently under evaluation in any other peer-reviewed publication.

\section{Author details}

${ }^{1}$ Division of Neuroradiology, University of Calgary, Calgary, Alberta, Canada. 2Division of Otolaryngology-Head and Neck Surgery, University of Calgary, Calgary, Alberta, Canada. ${ }^{3}$ The Ohlson Research Initiative, University of Calgary, Calgary, Alberta, Canada. ${ }^{4}$ Department of Diagnostic Imaging, Foothills Medical Centre, 1403-29 Street NW, Calgary, AB T2N 2T9, Canada.

Received: 6 March 2013 Accepted: 25 May 2013

Published: 5 June 2013

\section{References}

1. Ferlay J, Shin HR, Bray F, Forman D, Mathers C, Parkin DM: Estimates of worldwide burden of cancer in 2008: GLOBOCAN 2008. Int J Cancer 2010, 127:2893-2917.

2. DiPiro PJ, VanSonnenberg E, Tumeh SS, Ros PR: Volume and impact of second-opinion consultations by radiologists at a tertiary care cancer center: data. Acad Radiol 2002, 9:1430-1433. 
3. AJCC: Head and neck. In AJCC cancer staging manual. 7th edition. Edited by Edge SB, Byrd DR, Compton CC, Fritz AG, Greene FL, Trotti A. New York, NY: Springer; 2010:21-100

4. Fleiss JL: Measuring nominal scale agreement among many raters. Psychol Bull 1971, 76:378-382

5. Agresti A, Coull BA: Approximate is better than "exact" for interval estimation of binomial proportions. Am Stat 1998, 52:119-126.

6. Fisher RA: On the interpretation of $\times 2$ from contingency tables, and the calculation of P. J R Stat Soc 1922, 85:87-94

7. Landis JR, Koch GG: The measurement of observer agreement for categorical data. Biometrics 1977, 33:159-174.

8. Loevner LA, Sonners Al, Schulman BJ, Slawek K, Weber RS, Rosenthal DI, Moonis G, Chalian AA: Reinterpretation of cross-sectional images in patients with head and neck cancer in the setting of a multidisciplinary cancer center. AJNR Am J Neuroradiol 2002, 23:1622-1626.

9. Wheless SA, McKinney KA, Zanation AM: A prospective study of the clinical impact of a multidisciplinary head and neck tumor board. Otolaryngol Head Neck Surg 2010, 143:650-654

10. Loughrey GJ, Carrington BM, Anderson H, Dobson MJ, Lo Ying Ping F: The value of specialist oncological radiology review of cross-sectional imaging. Clin Radiol 1999, 54:149-154.

11. Tilleman EH, Phoa SS, Van Delden OM, Rauws EA, Van Gulik TM, Lameris JS Gouma DJ: Reinterpretation of radiological imaging in patients referred to a tertiary referral centre with a suspected pancreatic or hepatobiliary malignancy: impact on treatment strategy. Eur Radiol 2003, 13:1095-1099.

12. Gollub MJ, Panicek DM, Bach AM, Penalver A, Castellino RA: Clinical importance of reinterpretation of body $\mathrm{CT}$ scans obtained elsewhere in patients referred for care at a tertiary cancer center. Radiology 1999, 210:109-112.

13. Briggs GM, Flynn PA, Worthington M, Rennie I, McKinstry CS: The role of specialist neuroradiology second opinion reporting: is there added value? Clin Radiol 2008, 63:791-795.

14. Zan E, Yousem DM, Carone M, Lewin JS: Second-opinion consultations in neuroradiology. Radiology 2010, 255:135-141

15. Newman EA, Guest AB, Helvie MA, Roubidoux MA, Chang AE, Kleer CG, Diehl KM, Cimmino VM, Pierce L, Hayes D, Newman LA, Sabel MS: Changes in surgical management resulting from case review at a breast cancer multidisciplinary tumor board. Cancer 2006, 107:2346-2351.

16. Brook OR, Hakmon T, Brook A, Dudnik E, Kuten A, Engel A: The effect of a radiology conference consultation on cancer patients management. Ann Oncol 2011, 22:1204-1208.

17. Kronz JD, Westra WH, Epstein Jl: Mandatory second opinion surgical pathology at a large referral hospital. Cancer 1999, 86:2426-2435.

18. Bruner JM, Inouye L, Fuller GN, Langford LA: Diagnostic discrepancies and their clinical impact in a neuropathology referral practice. Cancer 1997, 79:796-803

19. Coblentz TR, Mills SE, Theodorescu D: Impact of second opinion pathology in the definitive management of patients with bladder carcinoma. Cancer 2001, 91:1284-1290.

20. Lueck N, Jensen C, Cohen MB, Weydert JA: Mandatory second opinion in cytopathology. Cancer 2009, 117:82-91.

21. Selman AE, Niemann TH, Fowler JM, Copeland LJ: Quality assurance of second opinion pathology in gynecologic oncology. Obstet Gynecol 1999, 94:302-306

22. Bejarano PA, Koehler A, Sherman KE: Second opinion pathology in liver biopsy interpretation. Am J Gastroenterol 2001, 96:3158-3164

23. Layfield LJ, Jones C, Rowe L, Gopez EV: Institutional review of outside cytology materials: a retrospective analysis of two institutions' experiences. Diagn Cytopathol 2002, 26:45-48

24. Hahm GK, Niemann TH, Lucas JG, Frankel WL: The value of second opinion in gastrointestinal and liver pathology. Arch Pathol Lab Med 2001, 125:736-739.

25. Westra WH, Kronz JD, Eisele DW: The impact of second opinion surgical pathology on the practice of head and neck surgery: a decade experience at a large referral hospital. Head Neck 2002, 24:684-693.

26. Hamady ZZ, Mather N, Lansdown MR, Davidson L, Maclennan KA: Surgical pathological second opinion in thyroid malignancy: impact on patients management and prognosis. Eur J Surg Oncol 2005, 31:74-77.

27. Bajaj J, Morgenstern N, Sugrue C, Wasserman J, Wasserman P: Clinical impact of second opinion in thyroid fine needle aspiration cytology (FNAC): A study of 922 interinstitutional consultations. Diagn Cytopathol 2012, 40:422-429.
28. Jones K, Jordan RC: Patterns of second-opinion diagnosis in oral and maxillofacial pathology. Oral Surg Oral Med Oral Pathol Oral Radiol Endod 2010, 109:865-869.

29. Wieske L, Wijers D, Richard E, Vergouwen MD, Stam J: Second opinions and tertiary referrals in neurology: a prospective observational study. J Neurol 2008, 255:1743-1749.

30. Srinivasan A, Mohan S, Mukherji SK: Biologic imaging of head and neck cancer: the present and the future. AJNR Am J Neuroradiol 2012, 33:586-594.

31. Manion E, Cohen MB, Weydert J: Mandatory second opinion in surgical pathology referral material: clinical consequences of major disagreements. Am J Surg Pathol 2008, 32:732-737.

32. Borgstede JP, Lewis RS, Bhargavan M, Sunshine JH: RADPEER quality assurance program: a multifacility study of interpretive disagreement rates. J Am Coll Radiol 2004, 1:59-65.

33. Berlin L: Accuracy of diagnostic procedures: has it improved over the past five decades? AJR Am J Roentgenol 2007, 188:1173-1178.

34. Babiarz LS, Yousem DM: Quality control in neuroradiology: discrepancies in image interpretation among academic neuroradiologists. AJNR Am J Neuroradiol 2012, 33:37-42.

doi:10.1186/1916-0216-42-39

Cite this article as: Lysack et al.: Impact of neuroradiologist second opinion on staging and management of head and neck cancer. Journal of Otolaryngology - Head and Neck Surgery 2013 42:39.

\section{Submit your next manuscript to BioMed Central and take full advantage of:}

- Convenient online submission

- Thorough peer review

- No space constraints or color figure charges

- Immediate publication on acceptance

- Inclusion in PubMed, CAS, Scopus and Google Scholar

- Research which is freely available for redistribution

Submit your manuscript at www.biomedcentral.com/submit
C BioMed Central 